\title{
A Successful Examination of Writing in Fixing Authorship-A Case Study
}

\author{
Reeta R Gupta ${ }^{1 *}$ and N Ravi ${ }^{2}$ \\ ${ }^{1}$ Central Forensic Science Laboratory (CFSL), India \\ ${ }^{2}$ Central Bureau of Investigation (CBI), India \\ *Corresponding author: Reeta R Gupta, Central Forensic Science Laboratory (CFSL), CGO Complex, Lodi Road, New Delhi, India
}

Submission: 韭 March 27, 2018; Published: 海 April 11, 2018

\begin{abstract}
This is a very important case related with examination of handwritings where the involvement of both bank personnel as well as fraudster was proved on the basis of handwriting examination report. It has thrown a serious challenge for the forensic document experts in solving this criminal case in order to fix authorship. The case was examined thoroughly by applying the principle of handwriting science and the investigating officer had collected the specimen of the suspected person very intelligently for providing suitable comparable material without showing the text content of questioned one. The present write-up is an attempt to unfold the journey of critical examination of the case related with conscious writings in order to reveal the authorship of hand written body writings on bank draft. The case was successfully solved and scientific evidence was accepted in the court of law and finally the suspected person was convicted.
\end{abstract}

Keywords: Handwriting; Forensic document examination

\section{Introduction}

Today a major problem of society is to save the community from criminal activities done by fraudsters. In the changing scenario of crime, the criminals are doing organized crime as a result; they may harm, oppress, exploit, abuse society and cost major economic loss. In view of these facts the role of forensic scientist becomes an important in assisting criminal justice system. The primary aim of forensic scientist is to obtain as much as scientific data available in particular exhibit of criminal case in the form of evidence to elucidate the scientific interpretation of fact related to the criminal activity. Once they do this the forensic scientist, during the deposition in the courts of law will be comfortable in furnishing proof of evidence to the court when various questions regarding the examination and opinion will be asked. Handwriting analysis is science of comparison of questioned with the supplied standards. During the process of comparison, all the principles of handwriting science is applied for identification of handwriting characteristics in order to find out the significant characteristic features in order to fix the authorship. After expression of any opinion related with criminal case, the success of Forensic Document examiners is extremely dependent upon the court disposition. Due to uniqueness in nature of examination in the field of questioned document, evidence produced by an expert during court testimony is very important. The present paper is a detailed case-study of one of the very important case.

\section{Brief Case History}

Briefly the case is explained that a fake demand draft contained the forged signatures signed by two signatory, one a chief manager and his junior a bank. A noted fraudster was the mastermind behind the crime had prepared the fake demand draft and formed a gang of fraudulent people who created fake account with involvement of bank personnel of Bangalore. Forgers invited fake invoice allegedly to purchase amusement item from a foreign firm. With the involvement of Chief Manager of Bank payment was processed to arrange to pay to foreign bank to the tune of Rupees Nine crore seventy lakhs, ninety thousand (Rs.9,70,90,000) through overseas branch. The overseas branch as per practice made telephonic enquiry to issuing branch regarding the payment of such a huge amount. Anticipating this enquiry, the chief manager intentionally took leave. The concern fraudster made fake letter head of bank and they made a request to the telephone department to divert the calls to another number where the fraudsters were using. Accordingly when the call was received from the overseas bank one of the fraudsters confirmed having sent the Demand Draft of said amount posing as chief manager. Subsequently the overseas branch cleared the payment of amount and the remittance was transferred to foreign bank. The Foreign bank subsequently raised some doubt about this transaction with the overseas branch which in turn reverted to the initiating branch and on the day the chief manager 
was on duty and he denied having forwarded the said fake demand draft. Thus the whole fraud came into light at the eleventh hour and bank was saved of huge of Rupees nine crore seventy lakhs ninety thousand amount [1-15].

\section{Detail of Case Examination}

The case deposited through the forwarding letter of CBI was an interesting one where an attempt was made to defraud a bank at the time of releasing of Rupees nine crore seventy lakh, ninety thousand. One of the gang members was an Assistant commandant of Karnataka Reserve Police who was suspected to be the author of the body writing on the questioned fake demand draft of the bank of the above mentioned amount shown in Figure 1 marked Q-26-A Q-26- B and Q-26-C. The questioned marked as Q-26-B and Q-26-C contain the signature of bank personnel on the demand draft. The questioned body writing marked Q-26-A was asked to be compare with the supplied specimen writings of suspected person. The investigating officer of the case very intelligently prepared a general text for dictating content of specimen for comparison with the questioned demand draft without showing the actual questioned Demand Draft (Figure 2). The said suspect freely given specimen shown in Figure 3 marked as S-1, which reflected his natural handwriting characteristics, written freely without any attempt to disguise or consciousness. On comparison with the questioned Demand Draft the specimen provided very suitable and satisfactory comparable material and authorship of body writing on the questioned demand draft was established after thorough scientific examination by applying the principle of handwriting science. As a research point of view, the investigating officer was requested to subsequently collect specimen after revealing the involvement of said suspect in preparation of fake demand draft. The suspect became very conscious after he knew of his involvement and he prepared specimen shown in Figure 4 \& 5 marked as S-2 and S-3 which was written in a consciousness with separate letters etc.

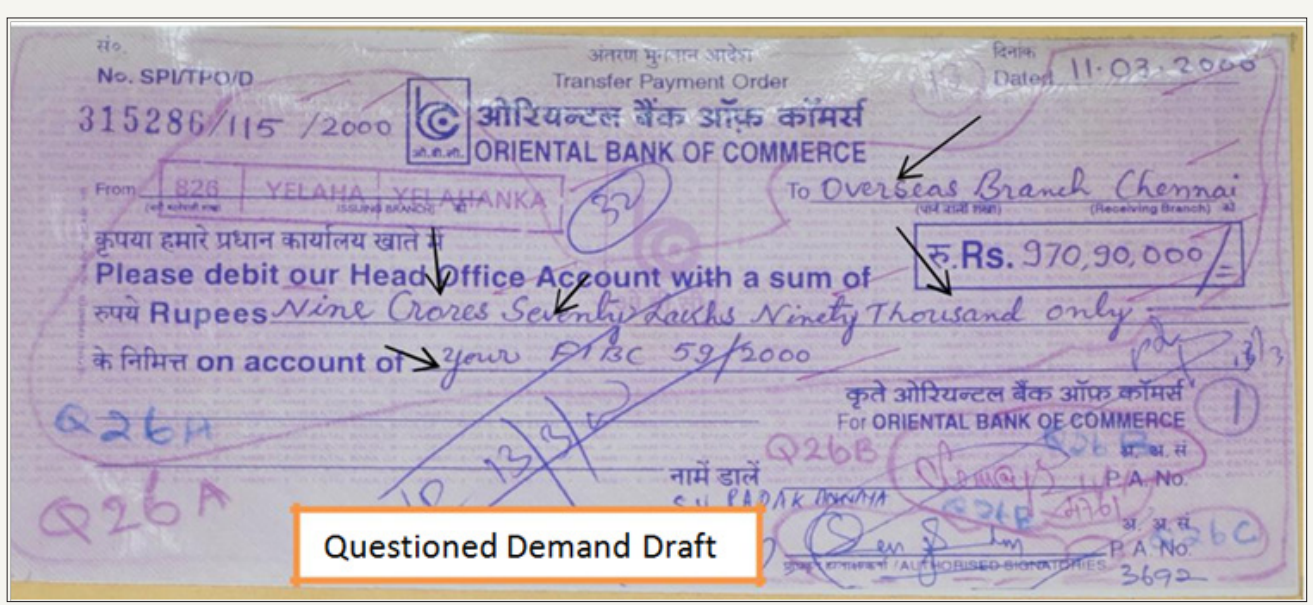

Figure 1: The Questioned writing on demand draft marked as Q-26 A (Body writing), Q-26 B and Q-26 C (Q-26 B and Q-26 C Signatures) Similar comparable words considered for examination and comparison with specimen are illustrated by arrows.

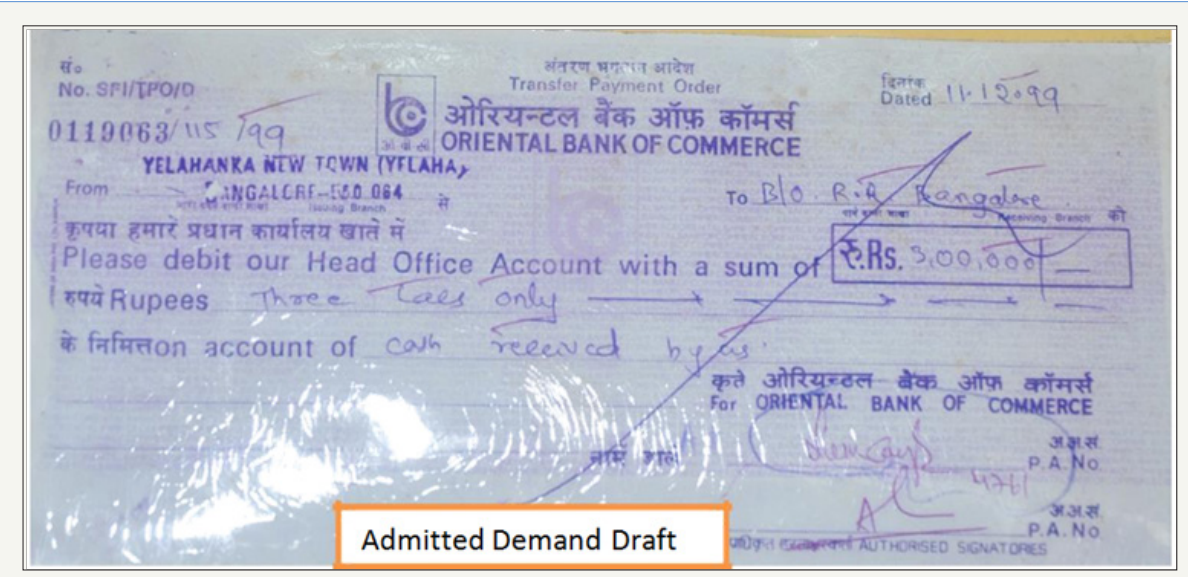

Figure 2: The admitted demand draft marked as A-1.

The body writing of questioned demand draft of oriental bank of commerce of Bangalore branch was marked as Q-26 A and two signatures were marked as Q-26 B and Q-26 C shown on Figure 1 and Admitted demand draft marked as A-1 is shown in Figure 2.
The specimen writings are illustrated in Figure 3-5, the specimens writing content were marked S-1 to S-3. The questioned body writings marked Q-26 A and specimen writing marked as S-1 to S-3 were compared and scientifically examined by applying the 
principle of handwriting science in order to identify the writing characteristic features to fix the authorship. Visual and optical examination of questioned and admitted demand draft revealed that there was a difference in visual color shade between the two sets.

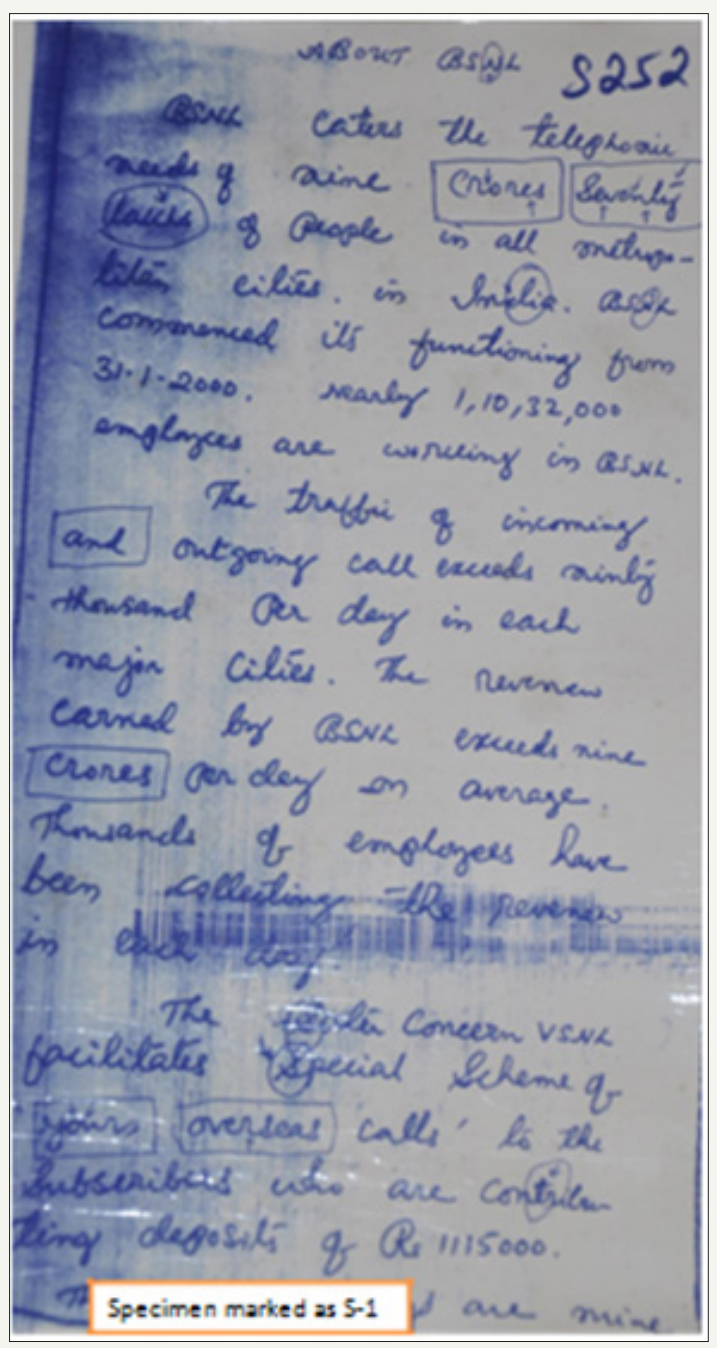

Figure 3: Specimen originally marked S-252 now marked S-1 showing the characteristic features of writing of suspected author considered for examination and comparison with questioned handwriting marked Q-26-A (words, capital letters, small letters and detailed execution of their connecting strokes).

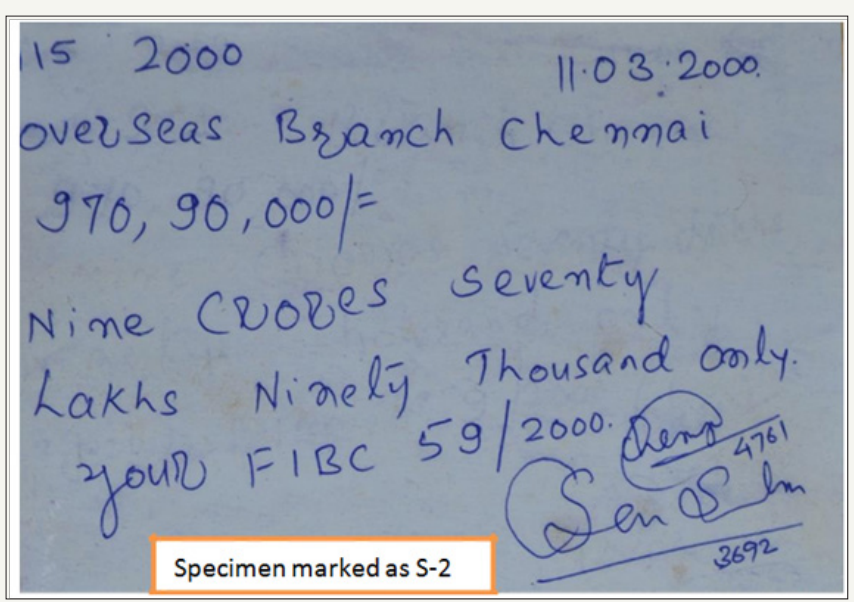

Figure 4: Specimen writings written with consciousness by the same suspected author marked as S-2 (Showing writing habit of suspected author). 


\section{Results and Discussion}

Table 1: Showing the comparison chart of characteristic handwriting features of questioned writing on demand draft (Body Writing) marked as Q-26-A and specimen writing of suspected person marked S-1 (peculiar similarities considered for comparison and examination between questioned and Specimen writings are illustrated above).

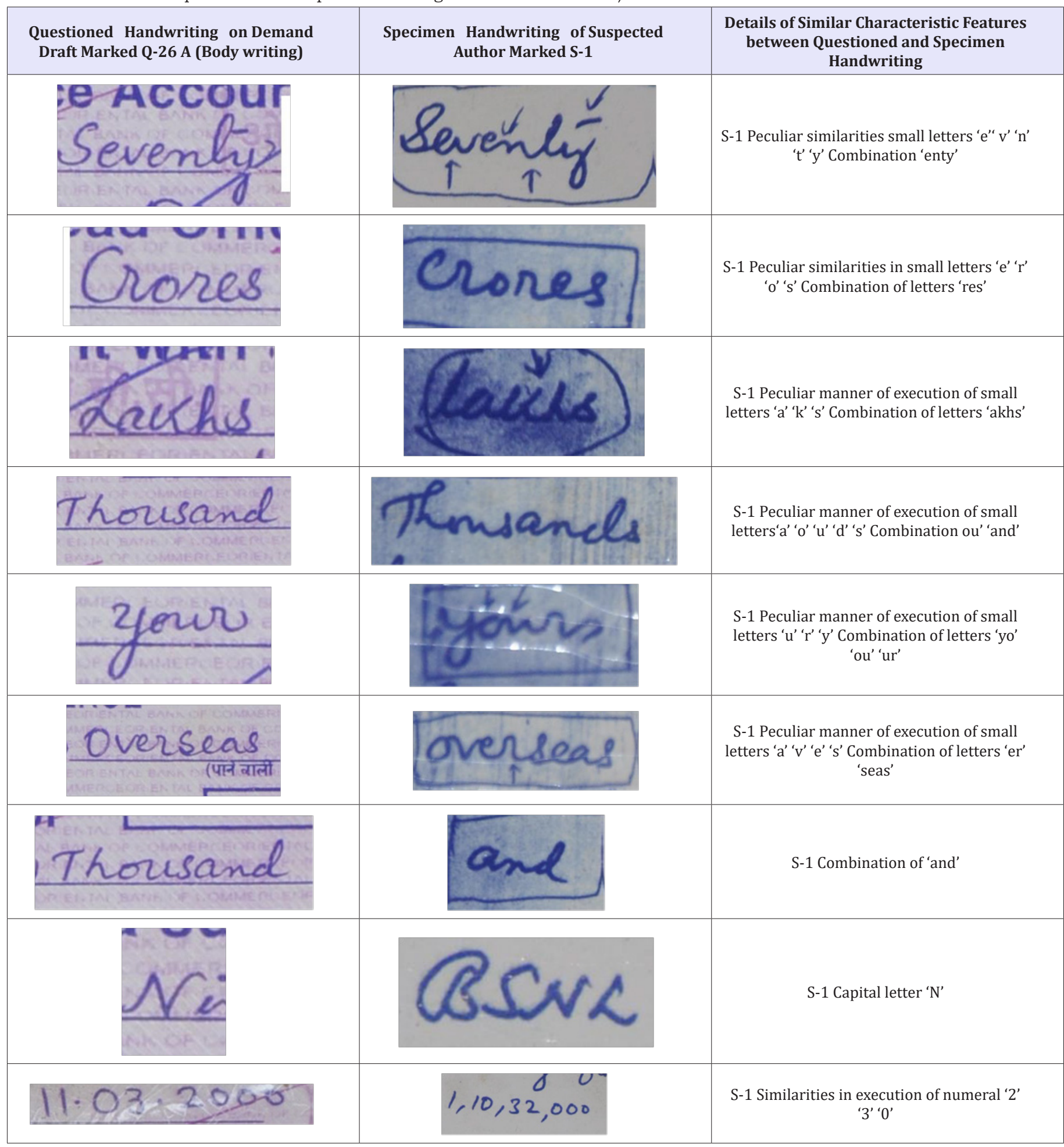

The said case was scientifically examined for comparison of questioned handwritten body writing of fake demand draft marked as Q-26 A shown in Figure 1 with the specimen writing marked S-1 to S-3 shown in Figure 3-5. During the course of examination it was observed that specimen S-1 shown in Figure 3 is written with free flow having excellent handwriting characteristic features in terms of identifying elements and features in the form of individual formation of letters as well as their movements of strokes, shape, size 
of individual letters, manner of connecting characters, curvatures in stokes while forming letters etc., which were considerable factors for examination as well as comparison with questioned ones and for expression of an opinion. The specimen writing marked S-4 and S-5 were written consciously, in these specimens writing, the suspected author after knowing his involvement became very much conscious and attempted to write letter in separate manner and consciously tries to change in formation of letters. The authorship of body writings on the questioned fake demand draft of such a huge amount was fixed with the specimen writings of supplied specimen illustrated in Figure 1 marked as S-1. The handwriting characteristics were thoroughly examined to account for the questioned handwriting characteristic features with specimen writing characteristics including their range and extent of natural variation. On the basis of cumulative consideration of detailed study of all significant identifying characteristic features of handwriting in execution of various letters and strokes in the letters formation as well as combination of letters in execution of words between questioned and specimens writing which led to the identification of authorship, the definite conclusion was drawn to form an opinion. The detailed comparative chart of peculiar characteristics features between questioned writing (body writing) on fake demand draft and specimen writing of suspected person which were considered as individual identifying characteristic features is illustrated in Table 1.

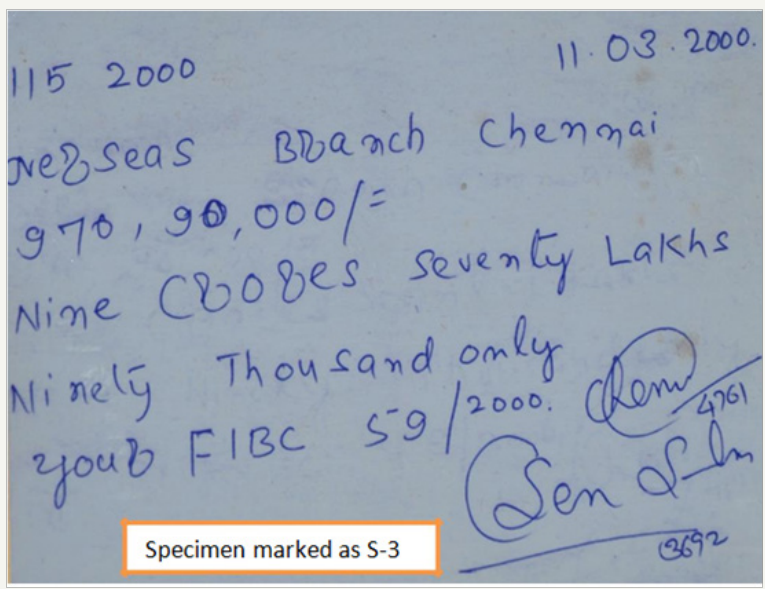

Figure 5: Specimen writings written with consciousness by the same suspected author marked as S-3(Showing writing habit of suspected author).

\section{Conclusion}

The phenomenon of natural variation in a human handwriting is one of the important factors in identification of handwriting science. Despite the natural variations, the individual possess, the range of unique significant identifying characteristic features depending upon his/her mental and muscular coordination which is the basis for the identification of the individual writings. The above mentioned criminal case was also examined on the basis of these fundament al handwriting principles. From the illustrated case, it is clear that the role of forensic document expert is very important to produce the proof of evidence in the court of law. On the basis of opinion expressed by the forensic document expert, the case was solved and criminals were convicted. This case was a unique one related with the involvement of bank personnel as well as fraudsters. The case is related with the organized crime which is very much harmful to our society in terms of economic loss. Fraudster in this criminal case, first made a plan to how to execute the crime, thus they formed a gang and involved bank personnel to execute the plan of the criminal master mind for defrauding a huge amount of money. This case is an excellent example of prudent team work spirit of investigating agency and forensic document expert.
The definite opinion of forensic document expert was accepted in the court and the suspected person was convicted. This is a best example of the role of forensic document experts in solving cases in assisting criminal justice system.

\section{References}

1. Osborn AS (1929) Questioned document. Forgeries, Nelson-Hall Co. Chicago, USA.

2. Harrison WR (1958) Suspect documents, their scientific examination. Nelson-Hall Co., Chicago, USA.

3. Hardless HR (1970) Disputed documents examination \& fingerprint identification. Law Book Company, Australia.

4. McCarthy JF, Winchester J (1973) The autopen. Journal of Forensic Science 18(4): 441-447.

5. Conway JVP (1978) Evidential documents. Chales C Thomas publisher ltd., USA.

6. Hilton O (1993) Scientific examination of questioned document. CRC Press, USA.

7. Harrison WR (1997) Suspected document: their scientific examination, second Indian Reprint, Universal Law Publishing Co. Pvt. Ltd, India.

8. Huber RA, Headrick AM (1999) Handwriting identification-facts and fundamentals. CRC Press, USA.

9. Morris RN (2000) Forensic handwriting identification: fundamental concepts and principles. Academic Press, USA. 
10. Siegal J, Knupfer G, Saukko P (2000) Encyclopedia of forensic sciences. Elsevier, USA.

11. Ellen D (2006) Scientific examination of documents- methods and techniques, $\left(3^{\text {rd }}\right.$ edn), CRC Press- Taylor \& Francis group, USA.

12. Hayes R (2006) Forensic handwriting examination-a definitive guide. ReedWrite press, Honolulu, USA
13. Kelly JS, Lindblom BS (2006) Scientific examination of questioned documents. CRC Press-Taylor \& Francis group, USA.

14. Koppenhaver KM (2007) Forensic document examination- principles and practice. Humana Press Inc., USA.

15. Koppenhaver KM (2015) Characteristic of authentic writing. The Scientific Journal of the International Association of Document Examiners 1: 17-22.
Creative Commons Attribution 4.0 International License

For possible submissions Click Here
Submit Article

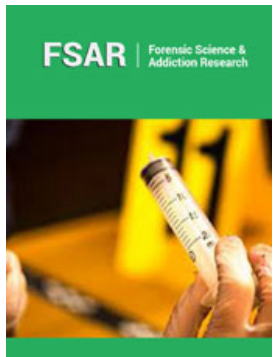

\section{Forensic Science \& Addiction Research}

\section{Benefits of Publishing with us}

- High-level peer review and editorial services

- Freely accessible online immediately upon publication

- Authors retain the copyright to their work

- Licensing it under a Creative Commons license

- Visibility through different online platforms 